\title{
15. Using Signed Numbers
}

If a numeric data item can be negative - it must be described in the DATA DIVISION as signed - otherwise the computer will assume it is always positive.

For example a data item called BANK-BALANCE is to hold a 6 digit number which may be positive (i.e. in credit) or negative (i.e. overdrawn).

The item may be declared as:

\section{BANK-BALANCE PIC S9(6).}

This will mean that the sign ('+' OR '-') takes up no extra space - it shares a character of storage with one of the numeric digits. So the length of this field is 6 characters.

The computer can use a number stored in the above format for arithmetic, etc but it is not suitable for numbers which are to be accepted from the keyboard or displayed on the screen; these should be declared as follows:

\section{BANK-BALANCE PIC S9(6) SIGN IS LEADING SEPARATE.}

In this case, the sign takes up a separate character and will be displayed on the screen together with the number (e.g. +001000 or -023500$)$ and must be typed on the keyboard in the same way.

(SIGN IS TRAILING SEPARATE may be used if you wish the sign to be keyed in or displayed at the end of the number).

\section{Exercises}

1. Write data declarations for the following fields:

a) TAX (6 digits - positive if tax is due, negative if a tax-refund is due);

b) TOTAL-ADJUSTMENTS-TO-PAY (5 digits - positive for an addition to salary, negative for a deduction).

2. Write a program which will ask for a pair of signed numbers, add them together and display the answer. Make sure your program will deal with various combinations of positive and negative numbers.

3. Write a program to carry out the following task.

For each credit-customer of a mail-order firm, the computer should ask for: name, address, account number, and account balance. If the account is 'in the red' the computer should display a statement for the customer stating the amount due; if the account is in credit (or zero) an addressed label should be displayed for a catalogue and order form to be sent out. 